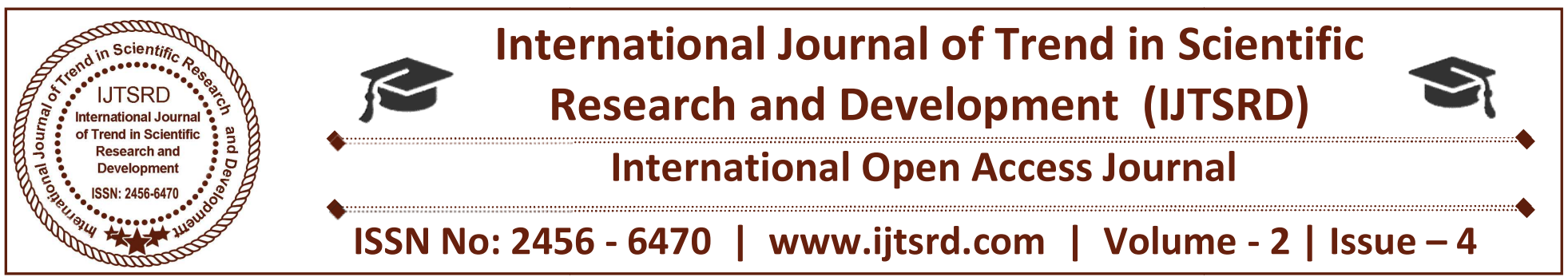

\title{
Students with Learning Disabilities and Inclusion
}

\author{
Saiju Khalid \\ Research Scholar, JIT University, Junjhunu, Rajasthan, India
}

\section{ABSTRACT}

Learning disability is a classification that includes several areas of functioning in which a person has difficulty learning in a typical manner, usually caused by an unknown factor or factors. Given the "difficulty learning in a typical manner", this does not exclude the ability to learn in a different manner. Therefore, some people can be more accurately described as having a "Learning Difference", thus avoiding any misconception of being disabled with a lack of ability to learn and possible negative stereotyping. The term inclusion captures, in one word, an all-embracing societal ideology. Regarding individuals with disabilities and special education, inclusion secures opportunities for students with disabilities to learn alongside their non-disabled peers in general education classrooms. While learning disability, learning disorder and learning difficulty are often used interchangeably, they differ in many ways. Disorder refers to significant learning problems in an academic area. These problems, however, are not enough to warrant an official diagnosis. Learning disability, on the other hand, is an official clinical diagnosis, whereby the individual meets certain criteria, as determined by a professional (psychologist, pediatrician, etc.). The difference is in degree, frequency, and intensity of reported symptoms and problems, and thus the two should not be confused. When the term "learning disorder" is used, it describes a group of disorders characterized by inadequate development of specific academic, language, and speech skills. Types of learning disorders include reading (dyslexia), mathematics (dyscalculia), writing (dysgraphia) and movement and coordination (dyspraxia).

\section{INTRODUCTION}

A learning disability (LD) is a type of learning difficult. It occurs once a person with normal or above average abilities for thinking and reasoning has suffering learning certain skills. A learning disability:

- Is a exact trouble in one region (for example, math or reading);

- Can range from slight to severe;

- Is not the same as an academic (thinking) incapacity (that was called mental retardation in the past). An academic in capacity reasons learning problems in many areas. She might, but she might not. There can be many causes for learning problems, like:

- Nearning disabilities;

- Lower intellectual ability (problems with thinking and reasoning in many areas);

- Pressures like emotional or behavioral problems.

Utmost learning debilities are existing at birth, and result from the way a child's brain matures. It is also probable for a kid to develop a learning disability after a brain harm or other problems that affect the brain (like epilepsy). Learning disabilities are not caused by poor parenting, poverty or a child's lack of motivation (although these things can definitely affect learning).

Learning disabilities can have major impacts on a child's life, because so much of a child's life at home, school and with peers depends on learning. But the greatest impact is at school. Children and youth with difficulties reading and writing will need support in subjects like history, geography, science and language arts. 
A learning disability might be even clearer when teachers use methods that make learning even more challenging for the child or teen. For example:

- Teaching by talking or lecturing, without using visual aids (like diagrams or written text) can make learning difficult for students who are 'visual' learners.

- Classrooms where there is an emphasis on writing will be difficult for students with writing disabilities.

- Technology that emphasizes the sharing of ideas has made a big difference for some students. Software is now available to:

- 'Read' text aloud. This allows the student to focus on the meaning of the information, rather than struggling with recognizing or sounding out words.

- Convert speech into writing. Again, this allows students to focus on what they want to say, rather than struggling with how to spell it and put it into a sentence that makes sense to others.

Children and youth with learning disabilities may also have problems with:

- Attention: Many children with learning disabilities also have Attention Deficit Hyperactivity Disorder (ADHD), making it difficult for them to focus and pay attention.

- Mood, anxiety and behavior: Learning disabilities can make school and learning more challenging. They may also affect social relationships. These stresses can affect moods, and cause anxiety and behavior problems. It's a two way street, though. Problems with mood, anxiety and behavior also affect learning.

- Listening and speaking (which may be part of a Communication Disorder).

- Coordinating large or small muscle movements. This can mean difficulties walking, running, throwing a ball or playing sports. It can also mean trouble with hand writing, drawing or other hand movements.

Students with learning disabilities may:

- Get poorer grades in just one subject area. For example, a student who does well in all subjects, but is struggling with math.

- Have to work very hard (harder than most other students) to get reasonable grades.
- Check hearing and vision. Problems hearing or seeing can have a big impact on learning. Start by taking your child to see your family doctor or pediatrician. You can also take your child to an optometrist for vision testing.

- Speak with the school about your concerns. School boards have psychologists who can assess your child (psycho-educational assessment). After these detailed tests about how your child learns, a psychologist can then decide if your child has a learning disability or not. Wait lists for this testing can be long. Some parents choose to pay to have a psychologist in private practice assess their child.

Parenting a child or teen with a learning disability

- Adjust your expectations to what your child or teen can do. Children and youth do well if they can. If they can't do well, it may be the learning disability that makes it hard for them to meet their parents' expectations.

- Be as patient as you can. The LD is a problem with the brain's 'wiring'-it's not your child's fault.

- Look for and encourage your child's strengths, interests, and abilities. Help your child or teen find chances to do well at things. You can also use your child's interests to help with school. For example, if your child has trouble reading, but loves hockey, books about hockey may help her work on her reading skills.

- Focus on the effort and the process, instead of grades or the 'outcome'.

- If your child speaks two languages (for example, Hindi and English), try to find a psychologist who speaks both of these languages. It may be that your child is having trouble learning in a 2 nd language.

Lighten the load: Some high school students may do better in school with a lighter course load. It's okay to take a little longer to finish high school-students take an extra year for many reasons. The diploma at the end is what's important, not the time it took.

- Don't let the learning disability 'define' your child or teen. Remind yourself (and your child!) of your child's strengths and interests.

- Share your wisdom: If you have a learning disability, please share your experience and coping strategies. Nobody will understand what your child is experiencing better than someone who's walked the same road. 
- Help youth take advantage of learning supports. Colleges and universities have many supports for students with learning disabilities. When students start at college or university, they need to bring a report that confirms the LD diagnosis and outlines the results of their psycho-educational assessment (done in the last two years). Students can then get the accommodations they need for classes, assignments or tests.

There are many ways to make learning easier for children and youth with LD:

Break down large tasks into smaller ones.

Teach specific skills. Children and youth may need help learning to organize their time, use an agenda or follow a schedule.

Accommodate the student. Change the learning environment to making learning easier by:

- Developing an Individual Education Plan (IEP) that is based on the student's needs and strengths. Ask the teacher if an IEP is possible.

- Offering a resource period in high school, so students have more time to complete school work.

- Special seating assignments.

- Creating assignments that match with the student's abilities.

- Modifying tests (for example, oral tests instead of written ones).

Teach 'compensatory' strategies. Teach students to use their learning strengths to 'go around' their learning disability. For example:

- Allow students who learn better by listening (auditory learners) to talk aloud to themselves to organize their thoughts.

- Use drawings, diagrams or demonstrations to explain things to students who learn better by seeing (visual learners).

Teach students to speak up for themselves (selfadvocacy skills). Teach students how to explain their unique learning needs to others and to ask for appropriate supports and accommodations.

The unknown factor is the disorder that affects the brain's ability to receive and process information. This disorder can make it problematic for a person to learn as quickly or in the same way as someone who is not affected by a learning disability. People with a learning disability have trouble performing specific types of skills or completing tasks if left to figure things out by themselves or if taught in conventional ways. The varieties of learning disabilities include reading (dyslexia), mathematics (dyscalculia), writing (dysgraphia) and movement and coordination (dyspraxia).

\section{DYSGRAPHIA}

Dysgraphiaaffects a person's handwriting ability and fine motor skills. A person with this specific learning disability may have problems including illegible handwriting, inconsistent spacing, poor spatial planning on paper, poor spelling, and difficulty composing writing as well as thinking and writing at the same time.

\section{Signs and Symptoms}

a) May have illegible printing and cursive writing (despite appropriate time and attention given the task)

b) Shows inconsistencies: mixtures of print and cursive, upper and lower case, or irregular sizes, shapes or slant of letters

c) Has unfinished words or letters, omitted words

d) Inconsistent spacing between words and letters

e) Exhibits strange wrist, body or paper position

f) Has difficulty pre-visualizing letter formation

g) Copying or writing is slow or labored

h) Shows poor spatial planning on paper

i) Has cramped or unusual grip/may complain of sore hand

j) Has great difficulty thinking and writing at the same time (taking notes, creative writing.)

\section{Strategies}

1. Suggest use of word processor

2. Avoid chastising student for sloppy, careless work

3. Use oral exams

4. Allow use of tape recorder for lectures

5. Allow the use of a note taker

6. Provide notes or outlines to reduce the amount of writing required

7. Reduce copying aspects of work (pre-printed math problems)

8. Allow use of wide rule paper and graph paper

9. Suggest use of pencil grips and /or specially designed writing aids

10. Provide alternatives to written assignments (video-taped reports, audio-taped reports) 


\section{DYSCALCULIA}

Dyscalculia affectsa person's ability to understand numbers and learn math facts. Individuals with this type of Learning Disability may also have poor comprehension of math symbols, may struggle with memorizing and organizing numbers, have difficulty telling time, or have trouble with counting.

\section{Signs and Symptoms}

a) Shows difficulty understanding concepts of place value, and quantity, number lines, positive and negative value, carrying and borrowing

b) Has difficulty understanding and doing word problems

c) Has difficulty sequencing information or events

d) Exhibits difficulty using steps involved in math operations

e) Shows difficulty understanding fractions

f) Is challenged making change and handling money?

g) Displays difficulty recognizing patterns when adding, subtracting, multiplying, or dividing

h) Has difficulty putting language to math processes

i) Has difficulty understanding concepts related to time such as days, weeks, months, seasons, quarters, etc.

j) Exhibits difficulty organizing problems on the page, keeping numbers lined up, following through on long division problems

\section{Strategies}

1. Allow use of fingers and scratch paper

2. Use diagrams and draw math concepts

3. Provide peer assistance

4. Suggest use of graph paper

5. Suggest use of colored pencils to differentiate problems

6. Work with manipulative

7. Draw pictures of word problems

8. Use mnemonic devices to learn steps of a math concept

9. Use rhythm and music to teach math facts and to set steps to a beat

10. Schedule computer time for the student for drill and practice Dysgraphia

11. Affects a person's handwriting ability and fine motor skills.

\section{DYSLEXIA}

Dyslexiaaffects reading and related language-based processing skills. The severity of this specific learning disability can differ in each individual but can affect reading fluency, decoding, reading comprehension, recall, writing, spelling, and sometimes speech and can exist along with other related disorders. Dyslexia is sometimes referred to as a Language-Based Learning Disability.

\section{Signs and Symptoms:}

a) Reads slowly and painfully

b) Experiences decoding errors, especially with the order of letters

c) Shows wide disparity between listening comprehension and reading comprehension of some text

d) Has trouble with spelling

e) May have difficulty with handwriting

f) Exhibits difficulty recalling known words

g) Has difficulty with written language

h) May experience difficulty with math computations

i) Decoding real words is better than nonsense words

j) Substitutes one small sight word for another: a, I, he, the, there, was

\section{Strategies:}

1. Provide a quiet area for activities like reading, answering comprehension questions

2. Use books on tape

3. Use books with large print and big spaces between lines

4. Provide a copy of lecture notes

5. Don't count spelling on history, science or other similar tests

6. Allow alternative forms for book reports

7. Allow the use of a laptop or other computer for inclass essays

8. Use multi-sensory teaching methods

9. Teach students to use logic rather than rote memory

10. Present material in small units

\section{DYSPRAXIA}

Problems with movement and coordination, language and speech. A disorder that is characterized by difficulty in muscle control, which causes problems with movement and coordination, language and speech, and can affect learning. Although not a 
learning disability, Dyspraxia often exists along with Dyslexia, Dyscalculia or ADHD.

\section{Signs and Symptoms}

a) Exhibits poor balance; may appear clumsy; may frequently stumble

b) Shows difficulty with motor planning

c) Demonstrates inability to coordinate both sides of the body

d) Has poor hand-eye coordination

e) Exhibits weakness in the ability to organize self and belongings

f) Shows possible sensitivity to touch

g) May be distressed by loud noises or constant noises like the ticking of a clock or someone tapping a pencil

h) May break things or choose toys that do not require skilled manipulation

i) Has difficulty with fine motor tasks such as coloring between the lines, putting puzzles together; cutting accurately or pasting neatly

j) Irritated by scratchy, rough, tight or heavy clothing

\section{Strategies}

1. Pre-set students for touch with verbal prompts, "I'm going to touch your right hand."

2. Avoid touching from behind or getting too close and make sure peers are aware of this

3. Provide a quiet place, without auditory or visual distractions, for testing, silent reading or work that requires great concentration

4. Warn the student when bells will ring or if a fire drill is scheduled

5. Whisper when working one to one with the child
6. Allow parents to provide earplugs or sterile waxes for noisy events such as assemblies

7. Make sure the parent knows about what is observed about the student in the classroom

8. Refer student for occupational therapy or sensory integration training

9. be cognizant of light and light sources that may be irritating to child

\section{CONCLUSION}

At first each students should be aware of the mistakes they are making while reading out and taking down. Finding out their mistakes is the maiden for the remedial classes. School creates multiple challenges for kids with LD, but with patients and effective plans, we can make our students thrive in the class room. Child psychologists can work with students, parents and teachers to put into practice theoretical and practical strategies for learning both inside and outside the class room. With consistent support, these strategies can help students meet learning challenges and experience success at learning centers.

\section{REFERENCE}

1. SNYDER.CR (Ed). (2000).handbook of hope; theory, measures, and applications.SAN DIEGO .CA; academic press

2. GARRETT, H.E (2007) statistics in psychology and education new Delhi; paragon international publishers. Internet reference also

3. ADVANI, L AND CHANDHA, A.2007) you and you are special child UBS publishers and distributers pvt.ltd

4. RAO, VK (2004) special education. NewDelhi; APH publishing. 